\title{
ORGANIC PHASE (EXTRACELLULAR MATRIX, OSTEOCYTE, BLOOD VESSEL) PRESERVATION IN FOSSIL TETRAPOD BONE: TEMPORAL AND ENVIRONMENTAL PATTERNS OF PRESERVATION
}

\author{
KAYLEIGH WIERSMA-WEYAND ${ }^{1 *}$, SASHIMA LÄBE ${ }^{1}$, P. \\ MARTIN SANDER $^{1}$ \\ ${ }^{1}$ Institute of Geosciences, University of Bonn, Nussallee 8, \\ 53115 Bonn, Germany (* correspondance: \\ kayleigh.wiersma@uni-bonn.de)
}

Hard tissues, such as bones and teeth, fossilize well, and provide the exceedingly rich fossil record of vertebrate evolution. In addition to their shape, the histological structure of bones is also preserved. Bone is a composite material consisting of an inorganic phase (IP) of about $70 \%$ by volume and an organic phase (OP) of $30 \%$ by volume. The OP consists mainly of collagen and is also known as the extracellular matrix (ECM). Since the 1960s, soft tissues and bone proteins have been detected in fossilized dinosaur bone, eroding the dogma that the OP is completely destroyed during fossilization. However, only recently were organic remains such as osteocytes, blood vessels, and sometimes ECM successfully liberated from fossilized bone by dissolution in weak organic acids. This discovery, however, led to a controversy over whether these organic remains represent original soft tissue preservation or biofilms produced by bonedegrading bacteria. We obtained a comprehensive sample of fossil tetrapod bone, covering the full range of tetrapod diversity and tetrapod-bearing depositional environments. The 40 samples range in age from 310 million years to 1,000 years old. The aim of our research is to develop hypotheses about the processes leading to the preservation of the OP and its degradation products and thus the conditions that are conducive to OP preservation. The bone samples were carefully digested in EDTA over a period of days and weeks, liberating osteocytes and sometimes blood vessels and ECM in the residue of 18 of the 40 samples. Microscope slides were created by washing the organic remains with ethanol, isopropyl alcohol, and xylene, and sealed with a fixing agent.The oldest preserved OP is from the Early Permian, and no bias towards more recent time periods is apparent. Remarkably, the fossil bone samples that preserved OP best are not from conservation deposits, but from regular fluvial and marine facies without any particular predictive factors for OP preservation. In particular, the lack of OP preservation in laminated anoxic sediments that preserves soft parts well, such as the Eocene Lake Messel oil shales and the Jurassic marine Posidonienschiefer Formation, is puzzling. 